\title{
RAZONES Y RECETAS PARA CONSTRUIR UN ESQUEMA DE CLASES
}

\section{Miguel A. Caínzos}

Universidad de Santiago de Compostela

\section{RESUMEN}

El objetivo de este trabajo es hacer una contribución crítica a la teoría de las clases sociales y al análisis clasista de la sociedad. Por un lado, presentaré algunas reflexiones generales sobre el sentido y el proceso de formación de "esquemas de clases». Por otro lado, propondré algunos criterios para construir un esquema de clases vinculado al proyecto de una reconstrucción analítica del programa de investigación materialista histórico.

«Las cuestiones son o bien cuestiones de palabras o bien cuestiones de cosas. Entiendo que son cuestiones de palabras aquellas en las que se indaga sobre las cosas por medio de las palabras y no aquellas en las que se indagan palabras.»

\section{(A. ARnauld y P. Nicole, La lógica o el arte de pensar, 1662.)}

El objetivo de este trabajo es hacer una contribución crítica a la teoría de las clases sociales y al análisis clasista de la sociedad. Por un lado, presentando algunas reflexiones generales sobre el sentido y el proceso de formación de los conceptos utilizados en la descripción y análisis de las estructuras de clase —es decir, de los «esquemas de clases»—. Por otro lado, sugiriendo la conveniencia de revisar los criterios que han inspirado el diseño de algunos de los más relevantes esquemas usados actualmente. Aunque mis observaciones con parcial- 
mente aplicables a los esquemas diseñados desde supuestos (meta)teóricos distintos, mi argumentación tiene como referente inmediato a los esquemas que están vinculados al proyecto de una reactivación y reconstrucción analítica del programa de investigación materialista histórico ${ }^{1}$. Mi propósito no es proponer un nuevo esquema, cerrado y completamente articulado, sino tan sólo definir algunas características que ha de poseer un esquema que, por su complejidad y flexibilidad, sea sensible a la multiplicidad de determinaciones en que, hoy más que nunca, consiste la realidad concreta de las sociedades tardocapitalistas.

Temo que esta declaración de intenciones sea recibida con escepticismo y necesite una justificación. Ante todo, porque más de un lector verá con condescendencia cualquier muestra de interés — así sea crítico- por la posible vitalidad de dos empresas teóricas —el materialismo histórico y el análisis de clase - que han sido objeto de tantas notas necrológicas ${ }^{2}$. Pero también por otro tipo de razones. Para empezar, son muchos los esquemas de clases que circulan en el mercado sociológico, así que la pretensión de aportar algo en este terreno puede parecer sintomática de una caída en el «complejo obsesivo de descubridor» que, según la célebre invectiva de Sorokin, es uno de los peores males que aquejan a la sociología contemporánea ${ }^{3}$. Además, los esquemas disponibles difieren tanto en su justificación teórica y (al menos a primera vista) tan poco en su construcción empírica y en su rendimiento explicativo, que muchos pensarán que los esfuerzos dedicados a su elaboración y refinamiento representan un lamentable derroche de energía ${ }^{4}$. Por último, algunos entienden que la construcción de un esquema de clases debe ser afrontada en términos pragmáticos y llevada a cabo «inductivamente» — desde el análisis clasista de fenómenos sociales específicos - y no "deductivamente» —en el marco de una teoría general de las clases 5 .

Todas estas reservas son comprensibles, pero creo tener buenas razones

1 Para una sintética caracterización de ese proyecto y una exposición de sus aportaciones sustantivas, véanse Wright (1994, cap. 8) y Mayer (1994), respectivamente.

${ }^{2}$ Es bien sabido que el materialismo histórico marxista ha sido declarado difunto de manera reiterada; también el análisis de clase ha tenido sus enterradores, desde Nisbet (1959) hasta Pakulski y Waters (1996). Aunque exageradas, esas declaraciones han identificado significativos cambios experimentados tanto por la sociedad como por la sociología en los últimos decenios. Sin embargo, parten de una imagen demasiado simple de la dinámica interna de las tradiciones de investigación y de cuáles son las reacciones posibles en sus momentos de crisis, que muy raramente pasan por su deconstrucción o abandono definitivo - cfr. una matizada visión de estas cuestiones en Alexander y Colomy (1992).

3 Sorokin (1956, 38 y ss.).

${ }^{4}$ En cuanto a las semejanzas de construcción empírica, véanse Carabaña (1995, sección I) y Burris (1990). En lo que respecta al rendimiento explicativo, el asunto es más complejo, pero muchos compartirán el comentario del propio Carabaña (1992) — y cfr. González (1992b y $1992 c$ ) — cuando, tras comparar la capacidad de cuatro esquemas para predecir los ingresos y observar que no hay grandes diferencias entre ellos, concluye que esto «resulta un poco decepcionante tras tantas discusiones teóricas sobre la verdadera naturaleza de las clases sociales».

5 Cfr. Carabaña $(1995,121$ y passim). 
—o, si se prefiere, buenas excusas - para ratificarme en el propósito expresado inicialmente. Parto de la elemental convicción de que tanto la capacidad explicativa de nuestras teorías como la posibilidad de producir un conocimiento de carácter acumulativo dependen en gran medida de la coherencia de nuestros conceptos básicos. Es cierto que una dedicación obsesiva al trabajo de formación conceptual deviene estéril y paralizadora si suplanta a la labor de construcción y evaluación de teorías o si se prolonga innecesariamente después de que ya ha desempeñado su función, pero no creo que éste sea el caso del debate sobre los diversos esquemas de clases. Y ello por dos motivos.

Por una parte, porque esta controversia se caracteriza no sólo —ni principalmente - por el enorme número de los esquemas disponibles, sino, sobre todo, por la existencia de bastante confusión en torno a qué es lo que realmente los diferencia y qué es lo que está en juego en su enfrentamiento. La consecuencia es que se mezclan entre sí agendas explicativas que son enteramente distintas y se toman como equivalentes conceptos que, en rigor, tienen sentidos y derivaciones divergentes. Esta confusión sólo puede ser despejada mediante una clara especificación de los fundamentos y alcance de las diferencias entre distintos esquemas y del nivel de la actividad teórica en que surgen esas diferencias, a fin de determinar qué información están destinados a seleccionar realmente unos y otros conceptos y qué hipótesis teóricas están implícitas en ellos.

Por otra parte, aunque es cierto que existe un gran número de estrategias de construcción de esquemas de clases, me parece que algunas de ellas no han sido desarrolladas hasta su límite. En particular, algunos prometedores intentos de revisar el concepto marxista de clase a fin de hacerlo compatible con una profunda reconstrucción del programa de investigación materialista-histórico que lo libere de los más insostenibles principios de su formulación clásica ${ }^{6}$ se han detenido antes de llegar a sus consecuencias últimas y, debido a ello, han acabado por regresar a posiciones más tradicionales y problemáticas. A mi juicio, esto hace necesaria una labor de formación conceptual que complete esa reconsideración del concepto de clase en un sentido distintivamente posmarxista.

En este artículo prestaré atención a los dos aspectos -clarificación previa y construcción- del trabajo de formación de conceptos. Por ello, mi exposición se divide en dos secciones independientes, fragmentos de un trabajo más extenso en preparación. En la sección I haré algunas reflexiones generales sobre los esquemas de clases y su proceso de construcción. Después de precisar qué tipo de conceptos son los esquemas de clases y qué condiciones deben cumplir (apartado 1), distinguiré varios niveles de actividad teórica o "clases de teoría» y sostendré que el proceso de formación de conceptos atraviesa todos esos niveles (apartado 2). Pasaré entonces a enunciar mi tesis central, a saber, que el diseño y contenido teórico de un esquema de clases resulta de decisiones adoptadas en cada uno de los distintos niveles de actividad teórica previamente dis-

${ }^{6}$ Pienso sobre todo en Wright $(1985,1989)$, pero también en Roemer (1982), Elster (1985) y Carling (1991). 
tinguidos, de manera que las fuentes de diversidad entre esquemas son múltiples y han de ser separadas cuidadosamente cuando se trata de compararlos y de evaluar su poder explicativo (apartado 3). Después de una breve recapitulación, señalaré algunas implicaciones de mi argumento, que apuntan a una reafirmación tanto de la relevancia del trabajo de formación conceptual como de la repercusión de la adopción de uno u otro esquema para la elaboración de teorías clasistas de la sociedad (apartado 4). En la sección II presentaré las líneas generales de una reconceptualización de las estructuras de clase vinculada a un proyecto de reconstrucción del materialismo histórico. Después de enunciar sintéticamente los supuestos generales que orientan esa reconceptualización (apartado 1) y de mostrar las limitaciones de las revisiones del concepto de clase llevadas a cabo hasta ahora en esa línea (apartado 2), defenderé la necesidad de diseñar un esquema de clases siguiendo una particular estrategia constructiva, que denominaré escalonada, multiaxial, inclusiva y pluralista (apartado 3).

\section{SOBRE LA CONSTRUCCION DE ESQUEMAS DE CLASES}

\section{Los «esquemas de clases» como clasificaciones sociológicas}

Como en cualquier otra ciencia, en sociología es frecuente el uso de clasificaciones, esto es, de sistemas de conceptos clasificatorios que distribuyen los elementos de un dominio en grupos definidos por la posesión de determinadas características comunes que funcionan como criterio clasificador ${ }^{7}$. Como el propio término indica, cada una de esas clasificaciones lleva consigo la delimitación de clases y, puesto que las clasificaciones posibles de distintos tipos de elementos sociales de acuerdo con distintos criterios son prácticamente infinitas, en principio habría que reconocer la posibilidad de una infinidad de conceptos sociológicos de clase mutuamente irreductibles, muchos de ellos potencialmente útiles en diferentes contextos analíticos. Vistas así las cosas, casi se podría tomar en su literalidad la provocadora máxima de Stinchcombe según la cual «la sociología sólo tiene una variable independiente: la clase» ${ }^{8}$, pero ello sería cierto a cambio de privar a este término de una significación teórica peculiar, al haberlo identificado previamente con "cualquier concepto clasificatorio» y, por tanto, haber equiparado sus sentidos lógico y sociológico 9 .

Sin embargo, la tradición sociológica ha tendido a utilizar el término "clase» en un sentido más restrictivo y lleno de contenido, si bien todavía abierto a interpretaciones divergentes. Por un lado, reservándolo para la clasifi-

7 Sobre los conceptos clasificatorios y su lugar en el trabajo científico se puede ver Mosterín (1984). Y, en directa referencia al concepto de clase, De Francisco (1992).

${ }^{8}$ Arthur Stinchcombe, citado por Wright $(1979,3)$.

9 Como parece proponer el ya citado Carabaña $(1994,1995)$. Es también lo que subyace al uso de expresiones como "clases de edad» o "clases de consumo». 
cación de unidades sociales atendiendo a relaciones de desigualdad social —no de mera diferenciación-. Por otro lado, aunque con menos consenso, aplicándolo específicamente a desigualdades de naturaleza económica. Nos enfrentamos entonces a una clasificación de elementos sociales (generalmente posiciones o actores que las ocupan) en términos de su forma de participación en estructuras de desigualdad económica consideradas básicas en el funcionamiento de las sociedades modernas: las relaciones de propiedad sobre recursos productivos y la división social y técnica del trabajo —o derivadas de ellas-. Es precisamente esta referencia la que explica tanto la fuerte carga normativa y política que ha acompañado al término "clase» desde su aparición hasta la actualidad, como el privilegiado lugar ocupado por este concepto en el discurso de una disciplina nacida, entre otras cosas, de la perplejidad ante las nuevas configuraciones adoptadas por aquellas estructuras como consecuencia de «la gran transformación» que dio origen al moderno capitalismo industrial.

Dando por supuesta esta doble restricción semántica, se puede entender un esquema de clases como un conjunto sistemático de conceptos (clasificatorios) que pretende ser representativo de (la distribución de elementos sociales en) una particular estructura socioeconómica de desigualdad, correspondientemente llamada «estructura de clases».

En cuanto clasificación, un esquema de clases debe cumplir las mismas condiciones de adecuación que ha de satisfacer cualquier otro conjunto de conceptos clasificatorios aspirante a ingresar en el vocabulario de una ciencia. Por una parte, condiciones formales, comunes a todas las ciencias. Por otra parte, condiciones materiales, especificadas según criterios peculiares de cada ciencia que traducen la común exigencia de que la clasificación sea natural o, lo que es igual, posea plausibilidad descriptiva y capacidad heurística.

La mejor manera de evaluar la «naturalidad» de una clasificación es someterla a una comparación sistemática con otra u otras clasificaciones alternativas del mismo dominio, a fin de determinar cuál de ellas es más fecunda científicamente. En lo que respecta a los esquemas de clases, esa comparación puede, en principio, realizarse mediante un proceso de "discriminación conceptual» que compara los esquemas rivales en dos sentidos: por un lado, en términos de su compatibilidad con principios teóricos generales a los cuales se vinculan jerárquicamente y que actúan como constricciones en el proceso de formación de los esquemas; por otro lado, mediante una labor de «discriminación empírica» que contrasta la consistencia de cada esquema con la evidencia empírica producida bajo la guía de aquellos principios ${ }^{10}$.

Sin embargo, las cosas se complican un poco en este punto, ya que el enfrentamiento entre esquemas de clases no siempre se limita a la contraposición de definiciones alternativas de un mismo objeto teórico dentro de un marco de supuestos básicos compartidos, sino que a menudo se deriva de una más radical discrepancia en la fijación de ese marco previo. Esta complicación

${ }^{10}$ Cfr. Wright (1985, 22 y ss., 136 y ss.) y Pawson (1989, cap. 9). 
no hace imposible la evaluación de los esquemas ni tiene por qué acarrear problemas extraordinariamente graves - no más graves, en todo caso, que los que recurrentemente se presentan en una práctica científica en la cual el pudorosamente llamado "pluralismo teórico" es endémico y se remonta hasta los más elevados niveles de abstracción-, pero obliga a ser cauteloso a la hora de precisar tanto las divergencias entre distintos esquemas como los niveles conceptuales en que aquéllas surgen. Es necesario, pues, separar estos diversos niveles, que corresponden a otros tantos momentos en el proceso de construcción -y estratos en el contenido "teórico»— de los esquemas de clases.

\section{Clases de teoría y formación de conceptos}

Para discernirlos usaré libremente la terminología propuesta por Wagner y Berger $^{11}$, que diferencian varias clases o niveles de actividad teórica: estrategias orientadoras, programas de investigación teórica, teorías-unidad y, finalmente, investigación aplicada.

Las estrategias orientadoras son constelaciones de decisiones metateóricas básicas: por un lado, postulados de ontología social, presuposiciones sustantivas y reglas metametodológicas, integrantes de los "fundamentos» de la estrategia; por otro lado, directrices más específicas que contribuyen a configurar la selección de problemas, la lógica de la explicación y el proceso de investigación empírica, formando la dimensión "operativa» de la estrategia. Por su parte, los programas de investigación consisten en conjuntos de teorías interrelacionadas entre sí, junto con investigación aplicada basada en esas teorías y relevante para su evaluación. Las relaciones entre teorías dentro de un programa pueden ser de diverso tipo, y van desde las relaciones de elaboración que predominan en los programas lineales hasta las de competencia que caracterizan a los programas competitivos, pasando por las relaciones de proliferación que son distintivas de los programas «ramificados». En cualquier caso, el programa posee un núcleo duro (inspirado por la estrategia orientadora bajo la cual se encuadra) que, siguiendo la clásica formulación lakatosiana, se debe proteger de las anomalías con que aquél se enfrente, recurriendo para ello a hipótesis auxiliares adicionales que deben incrementar el contenido empírico del programa - es decir, su capacidad para dar cuenta de nuevos hechos- y cuya construcción está ordenada por los criterios suministrados por su heurística positiva. Pero cabe admitir que en programas en fase relativamente temprana de constitución - como lo son, en general, los científico-sociales- la interpretación tanto de esos criterios como del propio núcleo puede ser objeto de controversia, con la consiguiente aparición de una pluralidad de pretendidos desarrollos

11 Inicialmente, en Wagner y Berger (1985); posteriormente, con nuevos matices y mayor elaboración, en otros lugares; véanse, por ejemplo, Berger, Wagner y Zelditch (1989), Zelditch (1992), Wagner (1992) y Berger y Zelditch (1993). 
del programa, lo cual en la práctica puede implicar la existencia de «ramas» o "subprogramas» divergentes o en competencia mutua ${ }^{12}$. En el interior de los programas se encuadran las teorias-unidad, que son conjuntos de proposiciones interrelacionadas de carácter abstracto y general que están dotados de contenido empírico, en cuanto describen y explican procesos empíricos específicos. Por último, tenemos la investigación aplicada, llevada a cabo en el marco de una determinada teoría y orientada a su contrastación o a su aplicación en la explicación de nuevos casos.

Entre estos diferentes niveles teóricos hay una relación bidireccional: imposición de constricciones sobre los niveles inferiores a fin de asegurar su consistencia con los compromisos asumidos en los niveles superiores; presiones conducentes a reajustes en los niveles superiores con objeto de asimilar los resultados obtenidos en los niveles inferiores, más próximos y sensibles a la evidencia empírica.

Lo que aquí me importa es que el proceso de "formación conceptual» tiene lugar, bajo diferentes formas y con desigual significación, en todos los niveles teóricos, desde la generación de las nociones más abstractas y elementales que definen una estrategia orientadora hasta la "construcción empírica» de categorías analíticas en que consiste el proceso de operacionalización de conceptos en la investigación aplicada. El paso de uno a otro nivel requiere una labor de transformación y reconstrucción de conceptos — reglada pero abierta- para adecuarlos a las necesidades de la actividad teórica en cada uno de los niveles y grados de abstracción. "Reglada» en el sentido de guiada y limitada por la relación jerárquica y constrictiva entre niveles, "abierta» en cuanto cada nivel determina un abanico de posibilidades cuya actualización y desarrollo depende de decisiones adoptadas en el nivel inferior.

\section{Formación de conceptos y teoría de clases}

En el caso que nos ocupa, concepciones y principios metateóricos muy básicos contribuyen a configurar un concepto general y abstracto de clase, caracterizado por ciertas propiedades estructurales y por estar orientado hacia la agenda explicativa que le asigna el programa de investigación en que se incardina; este concepto general se traduce en la construcción de un esquema de clases integrado por categorías clasificatorias que, finalmente, son operacionalizadas.

Así, pues, un esquema de clases es el resultado de un proceso de formación de conceptos que atraviesa los diferentes niveles de la actividad teórica que hemos distinguido. Por consiguiente, la contraposición entre diferentes modelos analíticos de clase puede originarse en cualquiera de esos niveles. A grandes rasgos, cabe encontrar:

${ }_{12}$ Como sugiere Burawoy (1990) a propósito del marxismo. 
A) oposición, en el plano de la investigación empírica, entre diferentes operacionalizaciones de un conjunto de categorías —un esquema de clases- sobre el cual hay acuerdo; diremos entonces que se contraponen usos distintos de un mismo esquema de clases;

B) oposición, en el interior de un programa de investigación, entre diferentes estrategias de construcción de las categorías integrantes del esquema de clases a partir de las constricciones derivadas de un conjunto de principios teóricos acerca de los cuales hay acuerdo - en particular, a partir de un concepto general y abstracto de clase comúnmente aceptado-; diremos entonces que hay diferencias de construcción -o de estrategia constructiva- entre los esquemas de clases en liza, interpretables como aspectos particulares de la divergencia o competencia entre subprogramas diferenciados dentro de un programa de investigación;

C) oposición entre definiciones antagónicas del concepto de clase en su mayor grado de generalidad y abstracción —esto es, de su agenda explicativa y sus propiedades estructurales_-, que va ligada a la pluralidad de programas de investigación bajo una misma estrategia orientadora; en este caso, podemos hablar de diferencias de contenido entre los esquemas; $y$, por último,

D) oposición entre estrategias orientadoras, que lleva consigo diferencias de fundamento entre los esquemas, esto es, desacuerdos en la definición del marco presuposicional en que se forma el concepto de clase, que pueden afectar a sus supuestos ontológicos, epistemológicos o sustantivos.

Todo esto puede resultar demasiado vago y abstracto, de manera que acaso sea oportuno hacer algunos comentarios sobre estos tipos de oposición con referencia a esquemas de clase bien conocidos.

A) Las diferencias de uso pasan a menudo desapercibidas, debido a que los criterios de operacionalización de esquemas dotados de fundamentación teórica explícita no suelen ser discutidos públicamente ${ }^{13}$. Sin embargo, es evidente que pueden tener efectos decisivos en la aplicación de un esquema de clases, y su confusión con diferencias surgidas en otro nivel teórico puede crear malentendidos y pseudodebates.

13 El de Wright (1985) es un caso excepcional, pues ha publicado los criterios de operacionalización de su esquema y los ha respaldado con una justificación de cada decisión. Todo lo contrario ocurre con Goldthorpe, cuyo esquema se caracteriza no sólo por una articulación teórica tan somera como deslizante — aunque cada vez más articulada: cfr. Goldthorpe (1982, 167 y ss.; 1987, 40-43; 1995, 314 y ss.) y Erikson y Goldthorpe (1993, 35 y ss.)—, sino también por una escasa transparencia acerca de cómo deben ser operacionalizadas sus categorías. Cabe suponer, por tanto, que las "diferencias de uso" son particularmente relevantes a la hora de comparar y valorar análisis que aplican este esquema. 
Una buena muestra de esto último lo proporcionan algunas de las críticas dirigidas por Gordon Marshall y sus colaboradores a los esquemas de clases propuestos por Erik Wright, concretamente aquellas que denuncian la existencia de individuos cuya categorización según Wright resulta contraintuitiva y aberrante, bien por ser incluidos bajo la rúbrica de managers cuando, bajo una inspección detallada, se observa que responden al perfil de "trabajador sin autoridad», bien por ser categorizados como «expertos» (en Wright II) o «semiautónomos» (en Wright I), debido a que aseguran poseer un alto grado de discreción en el ejercicio de sus funciones, cuando en realidad carecen de cualificación (caso de conserjes o limpiadores), o bien, finalmente, por ser conceptuados como "proletarios" a pesar de que poseen una elevada cualificación (así, los pilotos de líneas aéreas) ${ }^{14}$.

La pertinencia de estas críticas es algo que habría que juzgar empíricamente, mediante un examen detenido de los casos en cuestión, pero aquí podemos darla por supuesto ${ }^{15}$. Lo que importa es que Marshall et al. presentan estos casos contraintuitivos como si pusiesen de manifiesto deficiencias de contenido o de construcción en el esquema de Wright, cuando lo cierto es que podrían ser evitados mediante una simple revisión de sus criterios de operacionalización de sus categorías en un sentido más restrictivo (una más exigente definición operativa de autoridad) o más discriminante — separando y jerarquizando los indicadores de las dimensiones cognitiva (complejidad conceptual) y práctica (autocontrol) de la cualificación-. En definitiva, lo que Marshall et al. presentan como síntoma de una disputa entre esquemas generados en un nivel abstracto y elevado de la actividad teórica —enfrentamiento entre los esquemas de Wright y Goldthorpe y sus correlativos postulados neomarxistas y neoweberianos - responde, en realidad, a una discrepancia no expresa acerca de cómo habría que operacionalizar las categorías de Wright (lo cual, ciertamente, no impide que otras de las objeciones planteadas por Marshall et al. tengan un mayor alcance). Además, en esta mezcla de planos está latente una grave $-\mathrm{y}$ frecuente- confusión entre dos actividades o procesos totalmente distintos: de un lado, la clasificación de un dominio de individuos en clases; de otro lado, el diagnóstico o identificación de uno de esos individuos como perteneciente a una de tales clases previamente establecidas ${ }^{16}$. La operacionalización está orientada al "diagnóstico» y no afecta a la cuestión, lógicamente anterior, de la "construcción» del esquema — aunque, ciertamente, un esquema que no fuese susceptible de ninguna operacionalización adecuada sería inútil.

B) Las diferencias que he llamado de construcción tienen su ilustración más conspicua en la proliferación de esquemas de clases que se han propuesto

${ }^{14}$ Cfr. Marshall et al. (1988, cap. 3).

15 No obstante, véase Clement y Myles (1994, apéndice 2), donde se pone en duda la supuesta propensión de la propuesta de Wright a diagnosticar erróneamente la cualificación.

${ }^{16}$ Cfr. Mosterín (1984, 42-43). 
resolver el problema de las llamadas «nuevas clases medias» tomando como punto de partida y guía un concepto abstracto de clase explícitamente marxista.

Los proponentes de las diferentes soluciones podrían seguramente llegar a un cierto compromiso formal acerca de cuáles son los elementos teóricos primarios dentro del programa de investigación en que sus trabajos se inscriben -básicamente: materialismo histórico general (teoría de la historia), materialismo histórico especial (teoría del modo de producción capitalista), teoría de la revolución, teoría de la acción de clase ${ }^{17}$ - Todos ellos podrían, en particular, convenir en: i) definir las clases como "posiciones en las relaciones sociales de producción», lo cual lleva consigo cargar a la noción de clase con las notas semánticas derivadas de su asociación con las de relación, antagonismo, explotación, propiedad y producción; así como en ii) atribuirle una agenda explicativa en la cual ocupan un lugar preeminente el conflicto social intrasistémico, el cambio social transistémico y la articulación existente entre ambos, y en iii) entender que conflicto y - como consecuencia suya a largo plazo- cambio se siguen "naturalmente» de las desigualdades de clase, de tal manera que sus condiciones de realización deben ser determinadas por la teoría y su eventual ausencia ha de recibir una explicación específica. De este modo, todos aceptarían un mismo conjunto de constricciones teóricas al que deberían someterse en el proceso de construcción de esquemas destinados a cartografiar la estructura de clases capitalista ${ }^{18}$.

Sin embargo, estas constricciones teóricas, los elementos primarios del programa y la propia noción de «relaciones sociales de producción» son susceptibles de diversas interpretaciones y aplicaciones. Una consecuencia de ello es la aparición de pluralidad en la construcción de los conceptos de «posiciones de clase» específicas y, por tanto, en la respuesta a la cuestión de cuántas y cuáles son las clases cuya delimitación es analíticamente relevante en el capitalismo contemporáneo ${ }^{19}$ y cómo se han de definir las llamadas «clases medias». Por citar tan sólo unos cuantos ejemplos, Becker (1973), Poulantzas (1974), Carchedi (1977) y Wright (1978) asumen aquellos supuestos generales pero los traducen en esquemas de clases que van desde una agresiva reafirmación del bipolarismo marxiano (Becker) hasta una imagen muy fragmentada de la estructura de clases, con la inclusión de diversos tipos de "posiciones contradictorias» en las "clases medias» (Wright), y desde una definición muy amplia de la clase trabajadora, como formada por todos los asalariados (Becker), hasta una acotación de ésta extraordinariamente restrictiva, en cuanto compuesta únicamente por los productores que realizan trabajo excedente y no desempe-

${ }^{17}$ Cfr. una sintética caracterización de la concepción marxista clásica en Paramio (1993, sección II).

${ }^{18}$ Cfr. Wright (1985, cap. 2). Esto no significa que todos los autores sedicentemente marxistas acepten estas constricciones.

19 Entiéndase bien: analíticamente relevante respecto a los explananda a que se acaba de aludir en el párrafo anterior. Planteada en abstracto y sin esa particular referencia, la cuestión sería la de la «verdadera naturaleza de las clases» y carecería de sentido. 
ñan la "función del capital» (Carchedi) o, de modo aún más exigente, por los asalariados manuales productivos que no tienen ningún control sobre el proceso de trabajo (Poulantzas).

Estas discrepancias de categorización conllevan hipótesis contrapuestas acerca de la naturaleza de los procesos clasistas que tienen lugar en las sociedades capitalistas contemporáneas. Son, pues, sintomáticas de la asociación entre las diferencias de construcción de esquemas y las diferencias en la formulación de teorías-unidad ( $y$, eventualmente, de subprogramas) en el interior de un mismo programa de investigación.

C) Lo que he denominado "diferencia de contenido" tiene una buena ilustración en el clásico enfrentamiento entre los planteamientos weberianos y marxistas. Es verdad que ambos bandos son internamente heterogéneos en importantes aspectos, como se acaba de ver con el marxista. Es cierto también que se ha ido produciendo una paulatina convergencia entre unos y otros en lo que respecta a los criterios operativos utilizados en la construcción de esquemas de clases, de modo que las fronteras entre ellos parecen desdibujarse a ese respecto ${ }^{20}$. Pero esas eventuales semejanzas en la manera en que algunos marxistas y algunos weberianos describen ciertas estructuras de clases - y, por tanto, en cómo clasifican posiciones y actores- son secundarias con respecto a algo más esencial: su comprensión de en qué consisten esas estructuras, cómo funcionan y qué efectos generan y, en definitiva, su idea de qué es y por qué es importante una estructura de clases difieren notablemente entre sí.

Ello es así porque, en su forma más abstracta, un concepto de clase tiene como contenido implícito una teoría de las clases que cumple dos funciones. Por un lado, clarificar el proceso de emergencia de las posiciones y relaciones de clase. Por otro lado, especificar los efectos pertinentes de esas relaciones, es decir, aquellos efectos de los mecanismos generativos que el concepto de clase designa que son relevantes en la construcción de teorías clasistas de cualesquiera fenómenos sociales, por constituir mecanismos operantes en los procesos causales que dan lugar a tales fenómenos. Los conceptos marxista y weberiano de clase difieren en ambos aspectos.

Tradicionalmente, se ha descrito el desacuerdo respecto al primer aspecto como una oposición entre «centralidad de la producción» y "centralidad del mercado». Ese planteamiento ha sido puesto en cuestión con fuerza cada vez mayor en los últimos tiempos, pero creo que sigue teniendo cierta validez, con tal de que, pace Roemer, se reformule en términos de la oposición entre necesidad (marxistas) o no necesidad (weberianos) de referencia a la esfera de la producción en el surgimiento de las clases. En el segundo aspecto, la oposición entre marxistas y weberianos es más clara y remite al papel crucial que los primeros otorgan a la contradicción de intereses derivada de las relaciones de

${ }^{20}$ Cfr. Burris $(1987,1990)$. 
explotación frente al énfasis weberiano en la diferencia en las oportunidades vitales como efectos pertinentes de la estructura de clases ${ }^{21}$.

Las diferencias entre marxistas y weberianos en lo que respecta a su concepto abstracto de clase son correlativas a disparidades en los principios que guían sus respectivos programas de investigación. No me puedo parar aquí a explorar esas diferencias ${ }^{22}$. Me basta con resaltar que, así como un mismo concepto general de clase se puede traducir en distintos esquemas, también esquemas parcialmente coincidentes en su dimensión extensional —qué elementos caen en el interior de cada categoría - y en algunos de sus criterios operativos de construcción pueden diferir en sus hipótesis implícitas acerca de la naturaleza y comportamiento esperable de los elementos así clasificados y de las relaciones existentes entre ellos. Inevitablemente, esas diferencias hacen que hallazgos empíricos aparentemente coincidentes tengan sentidos notoriamente distintos según sean interpretados en un marco weberiano o marxista, lo cual constituye una típica manifestación de «sobredeterminación de los hechos empíricos por la teoría» ${ }^{23}$.

D) Las diferencias que he llamado de fundamento se originan en discrepancias sobre los principios y conceptos integrantes de las estrategias orientadoras que inspiran la formación de programas teóricos de investigación. Si, como he sugerido, los esquemas de clases son conjuntos de conceptos que tratan de representar ciertas estructuras de desigualdad, una obvia fuente de pluralidad viene dada por la diversidad de sentidos que los teóricos de las clases han atribuido a la noción de estructura, por sus contrapuestas concepciones de la relación entre «conceptos» $y$ «objetos» (y, por tanto, sobre qué significa decir que un concepto representa algo) y, finalmente, por sus distintos supuestos sobre la cuestión del estatuto ontológico de las estructuras sociales. Son todos ellos asuntos que remiten a algunos de los principales "dilemas teóricos» y disputas «interparadigmáticas» que atraviesan la sociología actual y su examen desborda los objetivos del presente texto ${ }^{24}$.

\section{Recapitulación e implicaciones}

En lugar de adentrarme en terreno tan arduo, me parece más sensato hacer una breve recapitulación y extraer algunas consecuencias de lo expuesto hasta aquí, a fin de proporcionar al lector una justificación retrospectiva para la

${ }^{21}$ Véase Wright (1995), para una suficiente discusión de este punto.

22 Como abierta expresión de las mismas, compárese Wright (1985, cap. 2; 1989, sec. 4) con la caracterización que Goldthorpe y Marshall (1992) hacen de su programa weberiano.

23 Tomo la expresión de Alexander (1989, 24).

24 Entre las innumerables discusiones de esos dilemas y debates merecen mención, en el contexto presente, las de Wilson (1983) y Johnson et al. (1984). Sobre la polisémica noción de estructura, véase Porpora (1987, 1989). 
tediosa excursión por lo obvio que han podido suponer las páginas precedentes - aunque la suya pueda ser, a los ojos de más de uno, la obviedad aparente de lo ilusorio.

Recapitulemos, pues. Un esquema de clases es una clasificación representativa de una cierta estructura de desigualdad económica. Esa clasificación se ve afectada —en su fundamento, contenido, construcción y uso- por decisiones tomadas en distintos niveles de actividad teórica. Ello significa que cuando se aplica un esquema de clases en un análisis concreto se están asumiendo, a menudo de manera inconsciente, decisiones sobre asuntos tan controvertidos como: 1) qué es una estructura social y en qué consiste su representación mediante conceptos (clasificatorios); 2) cuál es el núcleo semántico del concepto sociológico de clase, esto es, cuáles son sus propiedades estructurales, y cuál es la agenda explicativa que le viene atribuida por su incardinación y movilización en un cierto programa de investigación; 3) cuántas y cuáles son las clases diferenciadas en la particular estructura sometida a análisis y cuáles son los rasgos que comparten los elementos que forman parte de cada una de ellas; y 4) cómo se traducen esos rasgos en criterios operativos que hagan posible el diagnóstico de la clase a que pertenece cada elemento. La respuesta dada a cada una de estas preguntas limita las respuestas que se pueden dar a las siguientes.

Me parece que de todo ello se siguen dos consecuencias fundamentales. La primera es que cualquier intervención en el intrincado debate sobre la idoneidad de los diferentes esquemas de clases para el análisis de las sociedades contemporáneas, tanto si es evaluativa como si se dirige a la propuesta de un nuevo esquema, debe deslindar nítidamente los distintos niveles teóricos que se ven implicados en la discusión y no tiene otro remedio que incidir y adoptar decisiones en todos ellos. Y ello es aplicable también a quienes pretenden disolver el propio debate mostrando su futilidad y optando por el recurso pragmático a categorías generadas en contextos analíticos locales. Pues, aun aceptando que la formación de esquemas se pueda realizar desde el análisis en lugar de desde una previa teoría de las clases ${ }^{25}$, esa perspectiva sólo puede ser un punto de partida para un trabajo teórico adicional ${ }^{26}$. De lo contrario, el proceso de formación conceptual se detendrá en el nivel que he denominado de «construcción» del esquema, lo cual tiene al menos dos consecuencias negativas. Por una parte, hace que los conocimientos generados mediante la aplicación de un esquema definido con gran dependencia del contexto inmediato de análisis tengan también un valor limitado a su contexto genético, haciendo difícil la producción de conocimiento acumulable —es decir, se obstaculiza el paso de la obtención de conocimiento sobre un particular problema empírico en un particular contexto analítico a la obtención de conocimiento a partir de ese problema y más allá de ese específico contexto ${ }^{27}$. Por otra parte, conduce a

5 Cfr. nota 5, supra.

${ }^{26}$ Cfr. Breen y Rottman (1995b, 457-458).

27 Wright (1989: 321). 
dejar en la sombra, irreflexivamente, los supuestos previos (respecto a su contenido y su fundamento) en que inevitablemente se sustenta el esquema generado según el procedimiento «inductivo», socavando así su inteligibilidad. Y no es éste un problema que sólo se plantee desde una desmedida ambición de coherencia o desde el alocado anhelo de proveer una fundamentación absoluta y exclusiva a las categorías analíticas, sino que afecta a la capacidad del análisis clasista para proporcionar explicaciones genuinas de los procesos sociales que investiga. Esto me lleva a la segunda consecuencia de cuanto se ha expuesto en las páginas anteriores.

La comprensión del carácter complejo y estratificado del proceso de formación de conceptos y de su vinculación con la actividad teórica nos permite constatar que la tan frecuentemente señalada indiferencia entre esquemas de clases en lo que se refiere a su capacidad explicativa ${ }^{28}$ es tan sólo aparente - $\mathrm{O}$, para ser más exactos, no está suficientemente probada-. Quienes proclaman esa indiferencia sostienen que distintos esquemas han tenido un éxito semejante en la identificación de regularidades macrosociales consistentes en la persistente asociación entre la posición de clase y otras variables. Ahora bien, aun aceptando que esto sea cierto, no se impone la conclusión de que tales esquemas de clases tengan igual capacidad explicativa. Pues, como todo el mundo sabe (y, más que nadie, los sociólogos empíricos) y demasiada gente olvida (y, más que nadie, los sociólogos empiristas), la identificación de una asociación regular entre variables no constituye una explicación, sino un explanandum. Para tener una teoría explicativa es preciso mostrar que tal asociación refleja una conexión causal y hacer inteligible esta conexión mediante la especificación de los mecanismos a través de los cuales la variable clase produce los resultados que le atribuimos; es decir, hay que describir cómo opera la causa ${ }^{29}$. En el caso que nos ocupa, esto requiere que haya habido una previa clarificación teórica de cuáles son los mecanismos generativos que constituyen el referente del concepto de clase y cuáles son los efectos de esos mecanismos generativos que, a su vez, en su interrelación con otros determinantes, producen, en cuanto mecanismos operantes, ciertos fenómenos empíricos. Ahora bien, puesto que los distintos esquemas están respaldados por diferentes respuestas —implícitas o explícitas — a estas cuestiones, contendrán hipótesis distintas acerca de los procesos causales implicados en los fenómenos objeto de análisis y darán lugar a distintas comprensiones de dichos fenómenos. La evaluación comparativa del poder explicativo de los esquemas de clases se ha de centrar precisamente en su fertilidad en la producción de comprensiones causales satisfactorias de sus explananda. Y tanto la perspectiva temporal en que se haya de hacer esa evaluación como los criterios aplica-

28 Cfr. nota 4, supra.

29 Sobre causalidad e inteligibilidad como condiciones de toda explicación científica, veáse Van Parijs (1981, cap. 1; 1990, introducción), y una excelente síntesis en De Francisco (1996, cap. 3). Sobre la centralidad de la descripción de los mecanismos operantes en el análisis de clase, véase Breen y Rottman (1995a, esp. 50 y ss.; 1995b). 
bles en ella dependerán del nivel de actividad teórica y formación conceptual en que se origine la divergencia entre los esquemas sometidos a prueba. Si la discrepancia se sitúa en el ámbito de lo que he llamado el "contenido» del esquema - como ocurre, por ejemplo, en la polémica Goldthorpe/Wright-, la evaluación sólo podrá ser realizada a largo plazo, atendiendo a la productividad de los programas de investigación en que los esquemas son movilizados. Por consiguiente, la afirmación de la irrelevancia de optar por un esquema de clases u otro en lo que respecta a su capacidad explicativa es, como mínimo, prematura.

De las observaciones hechas en el párrafo anterior se deriva una última reafirmación de la importancia del trabajo de formación conceptual. Pues, aunque la determinación de los criterios que deben guiar la evaluación comparativa de las teorías producidas desde marcos interpretativos diferentes - e, indirectamente, de los propios marcos- es asunto complejo y controvertido, un principio plausible - aunque no excluyente ni definitivo- es el de la capacidad que un programa teórico (o una teoría) tiene de dar cuenta de los logros de los programas (o teorías) rivales. Es decir, de su capacidad no ya de aportar, desde las constricciones impuestas por su propios supuestos (meta)teóricos, explicaciones satisfactorias de lo que los programas (o teorías) rivales explican o de las anomalías con que se enfrentan, sino también de explicar por qué tienen esos éxitos y afrontan esas anomalías ${ }^{30}$. Ahora bien, la capacidad de un programa para formular esta clase de explicaciones —o, mejor, metaexplicaciones- e «incorporar» en su contenido los programas (o teorías) rivales depende en buena medida del grado de integración, ordenación sistemática y generalidad de sus elementos conceptuales. Una estrategia empirista de formación de conceptos dependientes de contextos analíticos locales tendría escasa potencialidad en este terreno.

En esta primera sección he intentado dar una imagen cabal de la relevancia y la complejidad del trabajo de formación conceptual en el caso de los esquemas de clases. La idea central es que, independientemente de que se comience desde los niveles más abstractos y generales de una teoría de las clases o, por el contrario, desde análisis clasistas específicos, es imprescindible recorrer, en uno u otro sentido, todas las fases del trabajo de formación de conceptos; o, al menos, es imprescindible hacerlo si queremos estar seguros de qué implicaciones tienen las categorías analíticas que usamos. En la sección II haré un breve ejercicio de formación de esquemas de clases, en lugar de hablar sobre ella, como he hecho hasta ahora.

30 Para una defensa de este "empirismo de segundo orden» como criterio evaluativo, véase Levey (1996). Una propuesta semejante pero menos sistemática se apunta en Wright (1989, 321-322). 


\section{PARA CONSTRUIR UN ESQUEMA DE CLASES POSMARXISTA}

Para ser consecuente con las conclusiones de la sección anterior, ese ejercicio debería atravesar todos los niveles del proceso de formación de conceptos. El espacio de que dispongo me obliga a imponerme unos objetivos mucho más modestos. Por una parte, dejaré a un lado tanto la especificación de los «fundamentos» del esquema como su operacionalización ${ }^{31}$. Por otra parte, me contentaré con esbozar su "contenido" y sus criterios de "construcción», sin ponerlos en práctica. Así, pues, en lugar de proponer un esquema articulado y formalizado, me limitaré a caracterizar la "estrategia constructiva» capaz de producir un esquema de clases congruente con un materialismo histórico reconstruido ${ }^{32}$.

\section{El concepto de clase y la reconstrucción del materialismo histórico}

Para ello, es necesario empezar por aclarar qué sentido se atribuye aquí a la reconstrucción del materialismo histórico y qué exigencias impone al diseño de un esquema de clases su vinculación al programa de investigación resultante de ella. Pues esa vinculación supone el sometimiento a las constricciones derivadas del papel que el concepto de clase desempeña en la formulación de los elementos teóricos definitorios de aquel programa, así como la necesidad de asumir la agenda explicativa que éste le asigna.

Empecemos por la agenda: el esquema de clases debe permitir clarificar las presiones y límites que la estructura de clases ejerce sobre la formación, conciencia y acción de clase y, en términos más generales, sobre diversos dominios de la conciencia y la acción sociales. Por tanto, el explanandum central es la acción colectiva ( $\mathrm{y}$ sus procesos desencadenantes), particularmente en cuanto emerge en un contexto de conflicto y tiene consecuencias relevantes para el cambio social. El alcance del análisis puede ampliarse hasta incluir los más diversos aspectos del comportamiento, conciencia y biografía individuales, englobando así el nivel micro, pero éstos no son los aspectos nucleares de la agenda del materialismo histórico.

Más estricta es la constricción derivada del carácter materialista del programa. En principio, ese materialismo puede ser entendido en dos sentidos. Puede significar 1) que las clases deben estar «referidas (por definición) a la distribución de ventajas y cargas materiales, esto es, de a) el ingreso y el trabajo, pero también posiblemente de b) el ejercicio del y la sumisión al poder», o 2) que

31 Respecto a los fundamentos, baste consignar que parto de una ontología y una concepción de la ciencia acordes con el realismo crítico bhaskariano — vid. Bhaskar (1979, 1989, 1993)—. Para una defensa de un fundamento semejante para la teoría y el análisis de clase, véase Wright (1987) y el subsiguiente debate en Brooks y Manza (1989).

32 Una primera formulación, provisional e incompleta, de tal esquema se puede encontrar en Caínzos (1995), de donde procede parte del contenido de esta sección. 
las clases deben estar «enraizadas (por definición) en las relaciones de propiedad que caracterizan el modo de producción de que se trate» ${ }^{33}$. Creo que, en rigor, un concepto de clase materialista-histórico ha de asumir ambos compromisos, tomando como base las relaciones de propiedad y especificando los «efectos pertinentes» del mecanismo causal que llamamos clase en términos abiertamente materialistas.

Pero estos dos aspectos — relaciones de propiedad y consecuencias de las relaciones de clase- requieren algún comentario adicional. Pues una reconstrucción del programa materialista histórico capaz de superar las anomalías encontradas por su formulación original exige proceder a una severa reformulación de sus elementos primarios y a la cancelación de algunas de sus teorías auxiliares ${ }^{34}$. E, inevitablemente, ello impone constricciones adicionales a la construcción de un esquema de clases.

La reconstrucción implica, en primer lugar, una redefinición de la teoría materialista de la historia orientada a darle un sentido débil y restringido, convirtiéndolo en una teoría de las trayectorias de cambio social que sea general, informativa $-\mathrm{y}$, por tanto, no trivial - pero abierta - y, por ello, no historicista-. Esto tiene varias consecuencias importantes para la construcción de un esquema de clases. La primera es que éste debe estar libre de todo supuesto unilinealista o desarrollista, ya sea implícito o explícito. Una teoría no historicista de las trayectorias históricas —en plural— es, en última instancia, una teoría de la posibilidad —o, de manera más modesta, de la imposibilidadhistórica en un horizonte estructurado de opciones. No puede ser erigida a partir de esquemas de clases que reduzcan solapadamente la pluralidad de esos futuros posibles a un desarrollo «necesario» o a una única bifurcación "verdadera» ontológicamente privilegiada — por ejemplo, entre "el capitalismo» y «el socialismo». Una segunda consecuencia es igualmente importante: el objetivo de delinear un mapa complejo de las "posibilidades históricas» —incluso aunque sea por la modesta vía negativa de formular «teoremas de imposibilidad histórica»— hace conveniente situar la tipología de estructuras económicas $-\mathrm{y}$, por tanto, de la estructura de clases- en niveles de abstracción inferiores al del modo de producción. En particular, esto invita a reconocer que las relaciones de propiedad han de ser entendidas como «un conjunto complejo de derechos y poderes» que pueden descomponerse y separarse entre sí en lugar de formar una "gestalt unitaria", y que el alcance del concepto de relaciones de propiedad real debe ser extendido hasta abarcar las relaciones de control efectivo sobre todos los tipos de bienes productivos, sin limitarse al capital y la fuerza de trabajo ${ }^{35}$.

Por otra parte, la reconstrucción del materialismo histórico exige también un debilitamiento considerable de su teoría de la acción social. Por un lado,

33 Van Parijs (1987, 215-216).

${ }^{34}$ Lo que sigue se basa en Paramio (1993), Cohen (1988, cap. 9) y Wright, Levine y Sober (1992).

35 Cfr. Wright (1994, 244), de donde procede el entrecomillado. 
atenuando la absoluta centralidad de la acción de clase para reconocer el papel de los intereses derivados de la participación de los individuos en otras estructuras no clasistas, lo cual deja abierta la cuestión de la forma y sentido que finalmente adopta la acción social. Pero, además y de manera especialmente importante, aquel debilitamiento consiste también en un reconocimiento del carácter complejo de los intereses derivados de la propia estructura de clases. Primero, porque esos intereses son diversos según el plazo temporal en que se consideren y a menudo son internamente inconsistentes, en la medida en que las estructuras de clase son en sí mismas complejas y los intereses que se derivan de cada uno de los niveles en que se articulan y en los cuales los actores participan (mercados, organizaciones, etc.) pueden colisionar entre sí. Y, en segundo lugar, porque los intereses de clase - de todas las posiciones de clase- no tienen necesariamente un carácter antagónico ni generan naturalmente conflicto, sino que pueden ser diferenciales y, por ello mismo, articulables en una perspectiva dinámica. Creo que esto tiene especial relevancia cuando se construyen esquemas que pretenden conceptualizar adecuadamente la naturaleza de las «nuevas clases medias», pero es un principio de validez general.

\section{Los limites de la revisión "analitica" del concepto marxista de clase}

Estos principios definen un marco general para abordar la labor de construir un esquema de clases. Aunque es suficientemente determinado como para establecer límites al abanico de estrategias constructivas compatibles con él y funciona, por tanto, como filtro para descartar otras opciones que responden a conceptos generales - y programas de investigación- diferentes, este marco deja abiertas diversas posibilidades a la hora de decidir cuántas y cuáles son las categorías integrantes del esquema de clases y qué criterios las definen. No es mi intención presentar aquí una tipología de las estrategias que, en la literatura sociológica reciente, han intentado construir un esquema de clases dentro de ese marco materialista histórico ${ }^{36}$. Para realizar mi objetivo de proponer una estrategia concreta es suficiente señalar que todas ellas tendrían que dar respuesta a, al menos, cuatro interrogantes básicos. Deberían estipular:

A) Qué imagen de las relaciones de propiedad subyace al esquema de clases. Hay que aclarar qué grado de complejidad se les atribuye y cuáles son los tipos de recursos cuya posesión es relevante para la definición de las clases.

B) Cómo se ha de entender el papel matricial de las relaciones de propiedad en la definición y generación de las clases y, por tanto, cuál es exactamente la estructura de relaciones que el esquema de clases pretende representar. Hay que precisar si se trata de definir clases de

36 Una tipología básica se encuentra en Caínzos (1995, sec. 2). 
propiedad (en estructuras distributivas), o clases de mercado (en estructuras de intercambio), o clases de producción (en estructuras funcionales), o si se trata de clases transversales a todas estas estructuras; y, en este último caso, es necesario especificar qué conexiones hay entre las distintas estructuras y cómo se produce la transición de una a otra.

C) Cuáles son los efectos pertinentes de la estructura de clases. Es decir, cuáles son las consecuencias de las relaciones de clase que les confieren relevancia analítica, permitiendo identificar mecanismos operantes en explicaciones clasistas de diversos tipos de fenómenos.

D) Cuál es el ámbito de cobertura del concepto de estructura de clases y, por tanto, cuál el dominio del esquema de clases.

Las respuestas dadas a estos interrogantes por los intentos de construir esquemas de clases desde la perspectiva del marxismo clásico son muy diversas, pero, con la inevitable simplificación que ello supone, se puede afirmar que una reconstrucción típico-ideal reuniría los siguientes rasgos:

A) Una concepción restrictiva y simple de las relaciones de propiedad, que otorga relevancia prácticamente exclusiva al control del capital y de la fuerza de trabajo, lo cual da lugar a una arraigada tendencia hacia la construcción de modelos de clase bipolares — aunque, a fin de acomodar la recalcitrante complejidad de la realidad social, ese bipolarismo sea a menudo corregido con la introducción de distinciones intraclasistas o con la definición de posiciones que tienen un estatus derivado de la relación entre las dos clases fundamentales.

B) Una notable confusión respecto a la segunda cuestión, oscilando entre una definición de las posiciones de clase en términos de propiedad, una definición puramente conductual (en términos de las prácticas productivas efectivamente realizadas por sus ocupantes) y una definición modal (en términos de las prácticas productivas que los actores se ven compelidos a realizar en virtud de la posesión de ciertas dotaciones de bienes económicos, es decir, estableciendo una conexión necesaria entre los criterios decisivos en los otros dos tipos de definición $)^{37}$.

C) La identificación de la relación de explotación como efecto cardinal de la estructura de clases. Sólo se puede hablar de relaciones de clase cuando hay explotación, aunque, con carácter secundario y no definitorio, se otorga significación a las relaciones de dominación implicadas en las prácticas de clase.

D) Una concepción restrictiva del ámbito de cobertura de los esquemas de clases, que puede adoptar dos formas típicas: la exclusión de los actores

37 De ahí la «confusión marxiana sobre las clases» de que habla Carling $(1991,1994)$. 
económicamente pasivos (inactivos o parados) del universo sobre el que se aplica el esquema clasificatorio, o su subsunción en una posición de clase a pesar de su incumplimiento de los criterios definitorios de esa posición, recurriendo para ello a criterios subsidiarios ad hoc. En cualquier caso, no hay categorías específicas para caracterizar la situación de los pasivos. En esto, los esquemas marxistas coinciden con la imagen convencional compartida por los esquemas ocupacionales nomarxistas $^{38}$.

Las principales revisiones del concepto marxista de clase realizadas en el marco de la reconstrucción analítica del materialismo histórico han tendido a:

A) Introducir una nueva concepción de las relaciones de propiedad, que pasan a ser consideradas como una trama compleja, basada en una tipología extensa de recursos productivos diferenciados en términos tanto materiales como sociales - esto es, tanto por ser fuerzas productivas cualitativamente distintas como porque su posesión se representa bajo formas específicas - . Puesto que cada tipo de recursos productivos es un eje independiente de las relaciones de propiedad y constituye la base para la emergencia de una relación de clase, se supera el bipolarismo capital/trabajo para dar paso a una matriz de relaciones de clase mutuamente irreductibles cuyas formas de articulación, interpenetración y jerarquización son históricamente variables y contingentes. (En lo que sigue, llamaré multiaxiales a los esquemas construidos a partir de esta distinción de una pluralidad de ejes de propiedad).

B) Inclinarse por una definición modal de las posiciones de clase o reproducir la "confusión marxiana»"

C) Ratificar e incluso reforzar el tradicional explotacionismo de los esquemas marxistas, ya sea demostrando formalmente la correspondencia clase-explotación o reafirmando la explotación como principio definidor de las clases. En todo caso, se insiste en que las relaciones de clase no implican necesariamente dominación y que, en caso de que ésta se dé, constituye un efecto de significación secundaria con respecto a la explotación.

D) Reproducir la concepción convencional, restrictiva del ámbito de cobertura de los esquemas de clases.

En mi opinión, esta reformulación «analítica» del concepto de clase tiene aspectos positivos, que proporcionan un fructífero punto de partida para una

38 Véase la crítica de esa visión convencional en Kreckel (1990).

39 Elster (1985) asume explícitamente la definición modal. La "confusión» clásica se reproduce en Wright (1985), que también ofrece la más acabada expresión de los otros tres rasgos que enumero en el texto. 
estrategia satisfactoria de construcción de un esquema de clases acorde con los principios de reconstrucción del materialismo histórico apuntados en el apartado anterior. Sin embargo, son insuficientes y, al retener demasiados supuestos del planteamiento marxista clásico, conducen a un callejón sin salida. No me puedo detener ahora a justificar esta afirmación, como sería deseable, pero debo al menos separar los elementos positivos y negativos de la aportación de los marxistas analíticos, representada canónicamente por el trabajo de Erik Wright $^{40}$.

Creo que su contribución decisiva es la adopción de una estrategia multiaxial en el diseño de su esquema de clases. Al margen de los perfiles concretos que éste adopta en el caso de Wright ${ }^{41}$, el principio del multiaxialismo me parece valioso por dos razones principales. Por un lado, porque proporciona un instrumento en principio apropiado para captar la especificidad de las llamadas "clases medias» sin atribuirles un sentido derivado o secundario y, de ese modo, maximiza la «adecuación material» del esquema a través del reconocimiento de los "poderes causales» propios de tales clases. Por otro lado, porque permite conciliar el mantenimiento de la sistematicidad, parsimonia y rigor exigidos por el sometimiento del esquema de clases a la condición de su encaje en una teoría materialista de la historia (en la cual los tipos de sociedad se caracterizan por las relaciones de propiedad) con la radical superación de toda concepción historicista del desarrollo social.

Sin embargo, estas virtualidades de la orientación multiaxial son cercenadas por los otros rasgos arriba enumerados. Dos de ellos son particularmente negativos. En primer lugar, la confusión que rodea al nexo establecido entre dotaciones de bienes productivos y posiciones de clase o, para ser más exactos, la tácita y no fundamentada comprensión de ese nexo bajo la forma de una aproblemática correspondencia que hace posible el salto de la definición de las posiciones de clase en términos de las relaciones de propiedad a su designación en términos de prácticas productivas sin especificar las mediaciones que intervienen en el paso de uno a otro nivel. El resultado es que se confunden conceptualmente entre sí las diferentes estructuras sociales en las cuales participan los actores ocupantes de posiciones de clase y se incurre en una mala abstracción ${ }^{42}$.

En segundo lugar, el mantenimiento del explotacionismo marxista. Este

40 En otros lugares he llevado a cabo un detenido análisis crítico de la teoría de las clases de Wright, llamando la atención tanto sobre su valor "revolucionario» dentro de la tradición marxista como sobre las limitaciones derivadas de su renuencia a romper con algunos elementos del programa clásico (Caínzos, 1990, 1994).

${ }_{41}$ Como es sabido, Wright (1985) parte de una tipología de recursos productivos que comprende el capital, lo que él denomina «bienes organizacionales» y «bienes de cualificación» $y$ - de manera implícita- la fuerza de trabajo, y construye una matriz de relaciones de clase que combina relaciones capitalistas, "estatistas» y "socialistas», cuyo cruce da lugar a la definición de doce posiciones de clase en las formaciones sociales capitalistas. 125).

${ }^{42}$ En este punto me parecen inapelables las observaciones críticas de Carabaña (1995, 124- 
explotacionismo tiene dos consecuencias que me parecen indeseables. Por una parte, obliga a Wright a mantener la convencional limitación de la cobertura de las categorías clasistas a los individuos económicamente activos, pues es evidente que, para una teoría que vincula clase y explotación, los pasivos representan una anomalía difícilmente soluble: no pueden ser explotados porque no generan producto alguno y considerarlos explotadores resulta contraintuitivo. Por otra parte, y de manera más importante, el explotacionismo es el responsable de la progresiva tendencia de Wright a considerar como secundarios los «bienes organizacionales» y los «bienes de cualificación», contraviniendo así el esencial multiaxialismo de su concepto de clase. Esa tendencia ya estaba presente desde el principio en Wright, adoptando la forma de una asimetría entre los diferentes tipos de bienes productivos en la configuración de la matriz de posiciones de clase, para la cual es indiferente la distribución de bienes organizacionales y de cualificación entre los propietarios de capital, sea cual sea el volumen de su propiedad de cada recurso ${ }^{43}$. Pero sus más negativos efectos se han puesto de manifiesto en la reacción de Wright ante las objeciones de sus críticos marxistas. Estos se oponían a la redefinición extensiva de las relaciones de propiedad de recursos productivos y a su uso como criterio de definición de posiciones de clase, y lo hacían denunciando la imposibilidad de especificar cuál es la conexión causal existente entre las situaciones de los explotadores y de los explotados en los casos de desigual distribución de bienes organizacionales y de cualificaciones (pues no está claro cuándo y por qué los expertos son inequívocamente explotadores de los no-expertos, y algo semejante ocurre con los directivos). Es decir, apuntaban la incapacidad del esquema de Wright -o al menos de algunas de sus categorías - para atenerse escrupulosamente al "postulado de necesaria correspondencia entre propiedad, clase y explotación». Ante esta situación, Wright optó por abandonar por completo el multiaxialismo para salvar el principio explotacionista; es decir, por reafirmar la vigencia del nexo clase-explotación a costa de consumar una completa liquidación de la significación clasista de aquellos recursos cuya desigual distribución no se traduce unívocamente en relaciones de explotación. En la práctica, esto equivale a restaurar tanto el "privilegio ontológico» de la relación capital/trabajo como el «cierre» del horizonte histórico teorizable desde una perspectiva materialista.

\section{Una nueva estrategia: multiaxial, escalonada, inclusiva, pluralista}

Como alternativa a este paso atrás, que conduce de vuelta a algunos de los callejones sin salida del programa marxista clásico, creo que cabe la posibilidad de optar por una salida que Wright ha desestimado: la de construir un esque-

${ }^{43}$ Cfr. González (1992a, 1992b), para una crítica de - y alternativa a - esta injustificada decisión de Wright. 
ma de clases mediante una radicalización de la estrategia multiaxial y el abandono del privilegio otorgado por el marxismo a las relaciones de explotación, sustituyéndolo por una comprensión más amplia y articulada de los determinantes de la asignación de intereses a los actores. Dos consecuencias se seguirían de ello. Por un lado, permitiría tomar las relaciones de propiedad como punto de partida de una definición escalonada de las posiciones de clase que distinguiese nítidamente las diferentes estructuras en que esa definición tiene lugar. Por otro lado, abriría la posibilidad de expandir el dominio del esquema de clases hasta incluir a los pasivos.

El resultado de optar por esta vía sería, en suma, la construcción de un esquema de clases multiaxial, escalonado, pluralista en la definición de los efectos pertinentes de las relaciones de clase, e inclusivo en la definición de su dominio. En lo que sigue, intentaré dar una idea aproximada de lo que ello significa.

A) La radicalización del multiaxialismo implica romper definitivamente con la inveterada propensión de los teóricos de las clases a absolutizar la relación capital/trabajo y a considerar como residuales otros determinantes de las relaciones de clase en las formaciones sociales capitalistas ${ }^{44}$. Para ello, es necesario ratificar la plena sustantividad, independencia, irreductibilidad y poder causal de los diferentes tipos de recursos productivos. Esto no impide atribuir al capital una primacía causal en la determinación de la dinámica de las relaciones de clase en las sociedades que llamamos capitalistas, lo cual equivaldría a desproveer de sentido a esta denominación. Lo único que quiere decir es que el capitalismo no es una realidad autocontenida y autoconstituyente y que aquella primacía es producto histórico y variable de los complejos nexos existentes entre diferentes tipos de relaciones de propiedad y de clase en formaciones sociales concretas, nexos que a su vez están sometidos a sobredeterminación por procesos exógenos a esa red de relaciones. El hecho de que otras relaciones y posiciones de clase emergiesen en estrecha conexión con las relaciones capital/trabajo y éstas les proporcionen su nicho institucional no significa que sean reductibles a ellas ${ }^{45}$.

El desarrollo de la estrategia multiaxial exige elaborar una tipología general de recursos productivos, lo cual desborda mis objetivos presentes. Me limitaré a hacer un vago esbozo de cuál podría ser su sentido.

Podemos comenzar reconociendo la existencia de dos tipos de recursos cualitativamente distintos en lo que respecta a sus condiciones de apropiación. Por un lado, los que, a falta de un término mejor, llamaré recursos monádicos; por otro lado, los que denominaré recursos posicionales.

Son monádicos los recursos que pueden ser objeto de posesión con independencia de su contexto de uso y, por tanto, al margen de la ocupación de posiciones o la realización de actividades económicas que comporten su movi-

44 Sobre esa tendencia, véanse las agudas observaciones de Mann (1993, 547 y ss.).

45 Así lo sugiere Urry $(1995,175)$ a propósito de la que él llama "clase de servicio». 
lización efectiva. $\mathrm{O}$, dicho de otra manera, con términos cuyo sentido precisaré más abajo, son recursos cuya posesión no requiere su activación ni la activación previa de otros recursos productivos. Los recursos monádicos cuya consideración es relevante para la construcción de un esquema de clases son: la tierra; el capital; la ciencia o, más exactamente, el conocimiento cientifico-técnico, y la fuerza de trabajo.

Por el contrario, son posicionales los recursos que no tienen existencia con independencia de su contexto de uso. Su posesión tiene como condición el ingreso en ciertas posiciones en redes sociales y el desempeño de ciertas actividades económicas, los cuales sólo son factibles como resultado de la previa activación de algún otro tipo de recurso productivo. Los recursos posicionales a tener en cuenta desde el punto de vista de la teoría de las clases tienen que ver con la diferenciación y especialización funcional dentro de unidades complejas o entre unidades (simples o complejas), y se presentan socialmente bajo la forma de mecanismos de movilización y asignación de los recursos productivos y de coordinación de los procesos de producción y distribución en un escenario caracterizado por un alto grado de desarrollo tanto de la "división técnica del proceso de trabajo» como de la "división del trabajo social» ${ }^{46}$. Es decir, mecanismos encargados de la ordenación de la producción y distribución en y entre procesos de trabajo en unidades productivas. La nómina de tales mecanismos es amplia, e incluye hogares, clanes, Estados, mercados, organizaciones y redes informales. No obstante, no todos tienen igual significación para la determinación de las relaciones de clase. Los mecanismos de mayor interés en el presente contexto son las organizaciones, que son objeto de control bajo la forma de detentación de autoridad y ocupación de posiciones estratégicas.

En este provisional catálogo de recursos hay algunos aspectos que merecen un breve comentario. En primer lugar, a fin de superar la imprecisión de la noción de cualificación ${ }^{47}$, se introduce una distinción categórica entre ciencia y fuerza de trabajo. La cualificación se puede entonces considerar como la capacidad y dimensión de variación - la sustancia, en suma- de la fuerza de trabajo. El conocimiento científico-técnico, por su parte, constituye una fuerza productiva distinta e irreductible, caracterizada por sus capacidades de innovación, de control y procesamiento de información, y de regulación tanto de los intercambios entre el sistema social y el entorno natural como de las relaciones entre los componentes del propio sistema. En términos levemente más operativos, el conocimiento científico se distingue de la cualificación por su grado de codificación formal, su capacidad de diseño y rediseño de tecnologías y su capacidad de afrontar y resolver problemas abstractos no previstos.

46 Sobre la importancia de distinguir ambos tipos de división del trabajo, sobre su distinción por los clásicos y su frecuente confusión en la sociología contemporánea, véase Kumar (1978, 83 y ss.).

47 Si se reconoce que no hay fuerza de trabajo que no tenga un cierto grado de cualificación, "la diferencia entre los expertos y los trabajadores simplemente "cualificados" sería meramente adjetiva y no sustancial» (González, 1992a, 39-40). 
Por otra parte, partiendo del reconocimiento de que la división del trabajo es, en sí misma, una poderosa fuerza productiva (y, por tanto, una base potencial para el surgimiento de relaciones de clase), se hace necesario discernir dos componentes de este recurso productivo y situar cada uno de ellos en el nivel conceptual que le corresponde. El primer aspecto es el del conocimiento relativo a la división del trabajo; el segundo, la división del trabajo considerada en sí misma.

En lo que se refiere al primer aspecto (conocimiento), parece sensato reconocer que, si la división del trabajo es una fuerza productiva, han de serlo también el conocimiento y las técnicas de los procesos de organización, coordinación de actividades, gestión y asignación eficiente de recursos que están directamente ligados a ella. En tal caso, el conocimiento de este género puede ser entendido como un tipo particular de recurso monádico. La cuestión que se suscita entonces es la de si se ha de englobar este específico "conocimiento organizativo» en el conocimiento científico-técnico en general -asumiendo que, en términos de la emergencia de clases, su estatuto es semejante- o se ha de considerar un mero atributo - esto es, una cierta clase de cualificaciónde la fuerza de trabajo o, por el contrario, se ha de separar de ambos, como un tipo de recurso sustantivamente diferente. Es posible encontrar buenas razones para favorecer cualquiera de estas opciones, de manera que no se puede zanjar la cuestión de manera concluyente. Por lo pronto, me inclino por una opción intermedia entre las dos primeras, que consiste en distinguir entre "conocimiento organizativo" y "cualificación organizativa», englobando a uno y otra en los tipos de recursos correspondientes: ciencia y fuerza de trabajo, en la medida en que reúnen los rasgos básicos que definen a éstos y los separan entre sí.

En cuanto al segundo aspecto, es decir, la propia división del trabajo considerada en sí misma como recurso bajo la forma de los medios de coordinación de las actividades económicas, hay dos cosas que me parecen resaltables. En primer lugar, el propio reconocimiento de su especificidad, consistente en la naturaleza posicional y no acumulable del control que los actores tienen sobre esos medios de coordinación. De ello se sigue que no es posible situar el control sobre la división del trabajo en el punto de partida de la definición de las clases, es decir, en el plano de las relaciones de propiedad, sino en un nivel conceptual propio, posterior a la introducción de los procesos de activación de los recursos a través de prácticas económicas en mercados y organizaciones. En segundo lugar, y en estrecha relación con este último punto, la distinción entre diversas formas sociales en que se ejerce el control sobre la división del trabajo. La construcción de un esquema de clases en toda su complejidad requeriría explorar el papel de todos los mecanismos de coordinación, prestando especial atención no sólo a las jerarquías de autoridad en las organizaciones, sino también a las posiciones de control en el Estado y en los mercados asimétricos y monopólicos, así como la interrelación entre ambos mecanismos, crucial para aprehender la peculiaridad del profesionalismo desde una perspectiva clasista. 
No me detendré más en este asunto. Baste de momento con tener presente la necesidad de considerar lo que llamaré relaciones de propiedad y relaciones de control como niveles diferentes en la definición de las posiciones de clase, correspondientes a los poderes y/o derechos de posesión sobre recursos monádicos y recursos posicionales, respectivamente.

B) Sobre la base de esa elemental distinción de tipos de recursos, la construcción de un esquema de clases debe realizarse de manera escalonada. Para ello es necesario clarificar la conexión existente entre, de un lado, las posiciones que ocupan los actores en los múltiples ejes de las relaciones de propiedad y, de otro, sus posiciones y prácticas económicas —esto es, mercantiles y productivas-, a través de la introducción de una variable intermedia entre ellas. Llamaré a esta variable activación, entendiéndola sencillamente como la movilización y uso de un recurso productivo para extraer de él un producto generador de bienestar. (A ello hay que añadir un segundo nexo, que vincula las posiciones y prácticas antedichas con sus "efectos pertinentes». En este apartado me referiré a la primera conexión, dejando la segunda para el próximo apartado.)

La variable de activación de los recursos productivos que un actor posee tiene dos componentes. Por una parte, el simple hecho del logro (o falta de logro) de la movilización del recurso a través de alguno de los canales institucionalmente disponibles para ella en una cierta formación social. Por otra parte, lo que llamaré la sede en que esa movilización se verifica, algo que en las sociedades modernas puede ocurrir, fundamentalmente, mediante la producción independiente y/o mediante la participación en algún tipo de mercado de factores de producción. Además, la variable de activación tiene dos determinantes. Por un lado, lo que podríamos llamar el plan de activación, es decir, el diseño que cada actor traza de la estrategia movilizadora que seguirá. Por otro lado, la capacidad de actualización o realización efectiva de ese plan.

En este marco, una posición de clase ha de ser entendida como una posición en la organización social de la producción y el intercambio cuya especificación se ha de hacer con referencia a dos momentos cualitativamente distintos: por un lado, en términos conductuales, a la naturaleza de las prácticas económicas realizadas por los actores que la ocupan y, por otro lado, al hecho de tener como base y precondición posibilitadora una determinada posición en las relaciones de propiedad —es decir, porque la posesión de una dotación mínima de recursos productivos de cierto tipo es requisito necesario pero no suficiente para su ocupación. Una obvia pero importante implicación es que en la definición de las posiciones de clase no se privilegia un único nivel del proceso económico, sino que están involucrados en ella todos los niveles de éste: la naturaleza de las posiciones de clase es determinada por las relaciones de propiedad, de intercambio y/o de producción, entendidas estas últimas en un sentido claramente distinguible del de las de propiedad, en cuanto son posteriores a $-\mathrm{o}$, en el caso de la producción independiente, se definen por- el proceso de acti- 
vación. $\mathrm{O}$, lo que es lo mismo, las clases se definen en la propiedad, en el mercado y en la producción. Se siguen de ahí dos consecuencias que merecen atención.

Por un lado, este escalonamiento y el correlativo reconocimiento del papel fundamental de la mediación mercantil en la transición contingente por parte del actor desde la mera posesión de recursos a la realización de prácticas económicas efectivas permiten una integración de los supuestos centrales del enfoque weberiano sin renunciar a la concesión de un papel pivotal a las relaciones de propiedad en cuanto base en la que están enraizadas las relaciones de clase. Es decir, podemos así dar su parte de razón a los weberianos y asumir toda la riqueza de sus análisis de los determinantes de los procesos de activación sin caer por ello en el relajamiento conceptual que implica la «tentación weberiana».

Por otro lado, la definición escalonada del concepto de clase está abierta a una doble interpretación, pluralista o sintética, según se entienda que cada uno de sus momentos define un tipo de clases (de propiedad, mercantiles, laborales ${ }^{48}$ o que constituye un aspecto o paso de una única definición de un solo conjunto de posiciones. Esa apertura o ambivalencia me parece deseable, porque la opción por una u otra interpretación será preferible en distintos contextos analíticos, dependiendo sobre todo de los explananda concretos y del nivel de complejidad y abstracción en que se sitúe el análisis. La primera opción tiene, sin duda, la virtud de permitir la identificación de clases de posiciones en el seno de estructuras especificas de diverso tipo - distributivas, de interdependencia y funcionales_-, aprehendiendo de manera inmediata la especificidad de las relaciones que las definen. La segunda opción, sin embargo, tiene la ventaja de proporcionar, mediante una superposición de las clasificaciones obtenidas en cada uno de esos niveles, un conjunto económico y manejable de categorías sintéticas de las diversas posiciones que ocupan los actores en virtud de sus formas de participación (o no participación) en aquellas estructuras. En definitiva, creo que estamos aquí no ante esquemas de clases alternativos, sino ante diferentes posibilidades de interpretación y uso de un mismo esquema. Aunque la interpretación "pluralista» es más escrupulosa conceptualmente, en cuanto distingue claramente entre diferentes estructuras cuya representación corresponde a distintos pasos o niveles en la construcción del esquema o incluso a esquemas distintos para cada estructura, también es cierto que su lectura "sintética» puede ser útil, siempre y cuando se tenga en cuenta que lo que se obtiene entonces son categorias aglutinadoras de posiciones y no posiciones estructurales en sentido estricto.

Una importante consecuencia de la adopción de una definición escalonada de las clases y de la inclusión de la variable de activación es proporcionar un adecuado punto de entrada a la introducción en el esquema de clases del papel

48 Como sugiere Carabaña (1994), que, lamentablemente, acaba por usar el concepto clase para designar toda clasificación social. 
causal mediador que tienen algunos determinantes exógenos en la lógica de los procesos clasistas. Estoy pensando particularmente en dos tipos de factores. Por un lado, los determinantes cognitivos y normativos que contribuyen a configurar el plan de activación de los recursos elaborado por los actores (plan que, debido justamente a la incidencia de tales factores, es irreductible al "plan de optimización» presentado por las definiciones modales de las clases construidas en términos del "modelo económico» de actor) y, de ese modo, median la relación entre propiedad y prácticas económicas. Por otro lado, un conjunto de factores estructurales $e$ institucionales que afectan directamente a la capacidad del actor para ejecutar el plan de activación. Particularmente significativos son, a este respecto, los efectos de la división sexual del trabajo, los determinantes adscriptivos de las prácticas de empleo, la regulación pública de los diferentes mercados —en particular, del de trabajo- y la variabilidad de los regímenes del Estado del Bienestar.

C) Una conceptualización pluralista de los efectos pertinentes de la estructura de clases lleva consigo la definición de una diversidad de bases relacionales de asignación de intereses y el reconocimiento del carácter variable $\mathrm{y}$, en algunos casos, teóricamente infradeterminado de la conexión entre ellas y las posiciones de clase. Dicho de otra manera: es preciso reconocer que ni todas las posiciones en la estructura de clases tienen efectos del mismo orden ni todas los generan a través de los mismos mecanismos.

Desde este punto de vista, las relaciones de clase pueden ser vistas en términos de un esquema ternario que conecta recursos productivos, prácticas económicas e intereses, con la variable de activación funcionando como variable intermedia entre los dos primeros componentes. Las relaciones de clases, vistas así, son un caso particular de un tipo más general de relaciones sociales a las que, a falta de un nombre mejor, llamaré «relaciones de desigualdad generadoras de intereses». Son éstas diferentes tipos de relaciones de las cuales se puede afirmar que implican una conexión causal entre tres conjuntos de términos: distribución de recursos de cualquier tipo, prácticas sociales e intereses relacionales que emergen como consecuencia de esas prácticas. La peculiaridad de las relaciones de clase radica aquí simplemente, de un lado, en que están basadas en la desigual distribución de un tipo específico de recursos: las fuerzas productivas, y, de otro lado, en que implican prácticas consistentes en formas particulares de uso de esos recursos.

Creo que se puede hacer una tipología básica de estas relaciones desigualitarias generadoras de intereses atendiendo a dos criterios. El primero es lo que llamaré el tipo de bien básico que las relaciones hacen desigualmente accesible a los actores. Se presupone que a todos los seres humanos se les puede atribuir un interés fundamental en acceder a tales bienes. Distingo dos tipos: bienestar material y autonomía. Por bienestar material entiendo la proporción entre trabajo, ocio y consumo, sin mayor especificación de las preferencias de los actores por incrementar uno u otro de los componentes de la proporción, sino atri- 
buyendo a todo actor un interés en maximizar la ratio entre ellos. Por su parte, la autonomía es entendida aquí como capacidad positiva para actuar en el modo y sentido que los actores se propongan, sin asumir contenidos u orientaciones particulares para esa actividad. Se presupone en lo que sigue que estos bienes básicos son transferibles y apropiables, es decir, que un actor puede incrementar su cantidad de uno de estos bienes extrayéndolo de otro u otros actores o, en términos más impersonales, extrayéndolo del volumen colectivamente disponible del bien.

Sobre esta base, es posible diferenciar varios tipos de desigualdades o asimetrías en la distribución de los bienes básicos en función de si implican o no transferencia neta de un actor a otro. Y, además, se puede hacer una segunda distinción, dentro de las asimetrías (o algunas de las asimetrías) que involucran transferencia, entre aquellas que comportan interacción entre los agentes y aquellas que no. El resultado de la aplicación de estos principios es la identificación de varios tipos de relaciones generadoras de intereses.

En primer lugar, la explotación, que implica la capacidad de incrementar el propio bienestar material mediante la reducción y apropiación del bienestar material de otros actores - fundamentalmente, apropiándose una parte del producto de su trabajo- . La explotación puede existir con o sin interacción entre los actores implicados en la relación, y hablamos entonces de explotación directa y explotación indirecta, respectivamente.

En segundo lugar, la dominación, que implica la capacidad de un actor para incrementar su capacidad de acción por medio de la reducción de la autonomía de otros actores — básicamente a través del establecimiento de una cadena de autoridad que permita emitir mandatos y regular la actividad de otros actores en modos que tengan valor instrumental para los fines del actor dominador, o imponiendo límites a la acción de otros actores que impliquen de manera directa una expansión en la capacidad de actuación del actor dominante.

Hay una fuerte homología entre explotación y dominación: son dos relaciones formalmente idénticas y materialmente diferentes. En ambos casos encontramos: a) desigualdad en la distribución de un atributo básico deseable; b) interdependencia entre los niveles de disposición de ese atributo, y c) que el fundamento de esa interdependencia se halla en la capacidad de los supraordinados para beneficiarse de - y, por tanto, instrumentalizar- las actividades - y, por tanto, el esfuerzo- de los subordinados. La explotación y la dominación son, pues, relaciones que implican reciprocidad asimétrica. Hay, sin embargo, otros dos tipos de relaciones que podrían ser entendidas como relaciones que implican asimetría sin reciprocidad. Son las que llamaré apropiación y dependencia.

En el caso de la apropiación, hay una asimetría en la capacidad de los actores de incrementar su bienestar material. Sin embargo, esta asimetría no tiene su causa en la existencia de transferencia de excedente de un actor a otro - $-\mathrm{y}$, por tanto, capacidad de beneficiarse inmediatamente del esfuerzo 
de éste-, sino en la desigual capacidad de los actores para apropiarse el excedente económico que ellos mismos contribuyen a producir. Ahora bien, esta asimetría sigue siendo relacional, puesto que la capacidad apropiativa de algunos actores depende de una desigual distribución de los recursos de los cuales tienen control y que los coloca en posiciones estratégicamente privilegiadas. Depende, pues, de la exclusión de otros actores del acceso a esos recursos, es decir, de un mecanismo de cierre social. Tenemos, así, cumplimiento de las condiciones a) y b) reseñadas en el párrafo anterior, pero no de la condición $c$ ).

Algo similar ocurre con la relación de dependencia, que tiene básicamente la misma estructura pero afecta a la distribución de la capacidad de acción. La dependencia implica precisamente una asimetría radical en la interdependencia de la acción social, de modo que algunos actores son absolutamente dependientes de las decisiones y acciones de otros sin que exista un efecto recíproco semejante al que sí existe en el caso de la dominación. Y, una vez más, tal asimetría es relacional en la medida en que su base se encuentra en el acceso desigual a los recursos. La relación de dependencia puede ser directa, cuando se presenta inmediatamente bajo la forma de una relación interpersonal, o media$d a$, cuando tiene lugar a través de un tercer actor.

Todos estos tipos de asimetría tienen obvias consecuencias para el bienestar y autonomía de los actores y, por tanto, constituyen la base para la asignación de intereses a los mismos. La evaluación del poder causal y relevancia de estos intereses y de su capacidad de funcionar como bases movilizables en la acción social sólo puede ser realizada en contextos histórico-sociales específicos. Por esa razón, una conceptualización comprehensiva de las relaciones de clase debe tomarlas en consideración a todas ellas y reconocer todos los intereses relacionales que ellas comportan como efectos pertinentes de las relaciones de clase. Un paso necesario en ese sentido es el de clarificar el estatus de cada posición de clases en cada una de las relaciones asignadoras de intereses.

D) Como he señalado anteriormente, la superación del explotacionismo abre la posibilidad de una definición inclusiva del ámbito de cobertura del esquema de clases, que permita incorporar tanto a los activos como a los pasivos y, por tanto, haga posible la conceptualización de unas específicas clases pasivas caracterizadas por su exclusión con respecto a la participación en el proceso económico, en su doble dimensión mercantil-productiva.

Como ya señalé anteriormente, la definición restringida del dominio del esquema de clases ha sido algo natural tanto para marxistas como para no-marxistas. La adopción de criterios técnico-ocupacionales o explotacionistas hacía que las posiciones pasivas fuesen ajenas al marco del análisis de clases. Ahora bien, la propuesta aquí esbozada está libre de tal limitación. Primero, porque parte de un rechazo del explotacionismo. Y, en segundo lugar, porque la estructura de clases tiene como referente último la división social del trabajo tal como es determinada por las relaciones de propiedad. Es preciso tener en 
cuenta la división técnica del trabajo en dos sentidos. Por un lado, como un tipo particular de recurso (posicional). Por otro lado, en el uso de la ocupación como elemento operacionalizador de algunas de las posiciones de clase. Sin embargo, ello no afecta a la lógica básica del esquema, pues no supone que la atribución de una ocupación a cada actor sea condición para asignarle una posición de clase; operacionalizar las posiciones recurriendo a la ocupación es bien diferente a la mera definición de clases ocupacionales ${ }^{49}$. Y es razonable considerar la no-ocupación actual como uno de los elementos definidores de la categoría de los pasivos.

Se podría pensar, sin embargo, que aunque no nos resulte necesario optar por una definición restrictiva del dominio del esquema, ello sería conveniente y, en todo caso, legítimo. Este posible argumento nos lleva a la cuestión de cuáles son los supuestos que proporcionan una aparente plausibilidad a la concepción restrictiva.

Tales supuestos, generalmente implícitos, son fundamentalmente tres. Primero, el de que todo actor posee una cierta dotación de recursos productivos: por lo menos una dotación mínima (una unidad) de fuerza de trabajo. Segundo, el de que los actores dependen de la «activación» (presente o pasada) de sus recursos productivos para la satisfacción de sus necesidades económicas, incluyendo las necesidades básicas de subsistencia; en ello consiste la "compulsión sorda" de las relaciones económicas, que niega a los actores cualquier posibilidad de sobrevivir al margen de ellas. Tercero, el de que todo poseedor de una dotación de recursos productivos es tendencialmente capaz de "activarlo» mediante su movilización estratégica en las redes económicas mercantiles y organizativas.

Podemos aceptar como válido el primer supuesto. Se podría sostener que hay actores que carecen de ninguna dotación productiva, en la medida en que ni siquiera poseen fuerza de trabajo. Por una parte, quienes sufren severas minusvalías que hacen enteramente imposible la participación en la actividad económica. Por otra parte, los individuos extremadamente infracualificados, cuya fuerza de trabajo puede en el límite tener un valor productivo prácticamente nulo. Sin embargo, dejaré a un lado estas dos posibles objeciones por no afectar a lo que, según creo, constituye el aspecto de más interés en la clarificación de la naturaleza de las clases pasivas.

Lo importante es que los otros dos supuestos son insostenibles. Lo es el de la necesidad de la activación, porque el desarrollo histórico de los derechos de ciudadanía y la consolidación de los Estados del Bienestar - aparte de otros factores adicionales como el papel de las redes informales en la provisión de medios de subsistencia- hacen que la participación en la economía productiva o en el intercambio mercantil tenga alternativas. Dicho de otro modo, los procesos históricos de creación de sistemas de provisión universalizada y la creación de lógicas no-mercantiles que se entrelazan con la lógica económica

${ }^{49}$ Cfr. Wright (1980). 
del capitalismo han llevado al surgimiento de categorías sociales excluidas de la vida económica activa. Y, lo que es más importante, esas categorías incluyen no sólo a sujetos que todavía no han participado o ya no participan en la producción o que han salido transitoriamente de ella, sino a otros cuya exclusión tiene un carácter estructural y duradero. En tales casos, la dependencia existente no es con respecto a la relación salarial, sino con respecto a los mecanismos públicos de provisión de bienestar o a mecanismos privados de ayuda.

A ello hay que añadir que tampoco el tercer supuesto es aceptable. Para empezar, por la sistemática asimetría entre el lado de la oferta y el de la demanda en los mercados de trabajo. Y segundo, porque el fin de la llamada "época del pleno empleo» — ligada a la aplicación de políticas keynesianas y, en términos más generales, a la vigencia del fordismo- hace especialmente manifiesto que la posesión de fuerza de trabajo, aunque vaya unida a la teórica inexistencia de barreras adscriptivas en el mercado de trabajo y al reconocimiento legal del derecho universal al trabajo, está lejos de conllevar de manera inequívoca la capacidad del ejercicio de ese derecho y, por tanto, la integración efectiva en la vida económica.

En definitiva, ni todos los individuos tienen que entrar en las relaciones sociales de producción e intercambio ni todos pueden hacerlo. Las desigualdades de clase, entonces, tienen que ver tanto con las relaciones distributivas, de intercambio y funcionales que se dan dentro de las esferas de la producción y el mercado como con la propia delimitación de la frontera entre incluidos y excluidos de la participación en ellas.

En la sección I de este artículo expuse algunas de las razones por las que el trabajo de construcción de esquemas de clases sigue siendo útil e incluso necesario. En la sección II he esbozado una receta para construir un esquema de clases acorde con un materialismo histórico posmarxista, apostando por una óptica multiaxial, escalonada, inclusiva y pluralista. La presentación y defensa del esquema resultante ha de esperar a una próxima ocasión, pero el lector impaciente puede ir haciendo sus propios ensayos de indagación sobre las cosas, aunque sea por medio de las palabras.

\section{REFERENCIAS BIBLIOGRAFICAS}

Alexander, J. C. (1989): Structure and Meaning. Relinking Classical Sociology, Nueva York, Columbia University Press.

Alexander, J. C., y Colomy, P. (1992): «Traditions and Competition: Preface to a Postpositivist Approach to Knowledge Cumulation», en G. Ritzer (ed.), Metatheorizing, Londres, Sage.

Becker, J. F. (1973): "Class Structure and Conflict in the Managerial Phase» (partes 1 y 2), Science and Society, 37 (3): 257-277, y 37 (4): 437-453.

Berger, J.; Wagner, D., y Zelditch, M. (1989): "Theory Growth, Social Processes, and Metatheory», en J. H. Turner (ed.), Theory Building in Sociology, Londres, Sage.

Berger, J., y Zelditch, M. (1993): «Orienting Strategies and Theory Growth», en J. Berger y M. Zelditch (eds.), Theoretical Research Programs: Studies in the Growth of Theory, Stanford, Stanford University Press. 
BHASKaR, R. (1979): The Possibility of Naturalism, Londres, Harvester Wheatsheaf.

- (1989): Reclaiming Reality, Londres, Verso.

- (1993): Dialectic: The Pulse of Freedom, Londres, Verso.

Breen, R., y Rottman, D. (1995a): Class Stratification. A Comparative Perspective, Londres, Harvester Wheatsheaf.

- (1995b): «Class Analysis and Class Theory», Sociology, 29 (3): 453-473.

Brooks, E. C., y MAnZA, J. (eds.) (1989): «A Symposium on the Foundations of Radical Social Science», monográfico de Berkeley Journal of Sociology, XXXIV.

Burawoy, M. (1990): "Marxism as Science: Historical Challenges and Theoretical Growth", American Sociological Review, 55: 775-793.

Burris, V. (1987): "The Neo-Marxist Synthesis of Marx and Weber on Class», en N. Wiley (ed.), The Marx-Weber Debate, Londres, Sage.

- (1990): "Classes in Contemporary Capitalist Society: Recent Marxist and Weberian Perspectives», en S. R. Clegg (ed.), Organization Theory and Class Analysis, Nueva York, Walter de Gruyter.

Caínzos, M. A. (1990): «Explotación, dominación y estructura de clase. Notas críticas sobre Erik Olin Wright y el análisis de clase», Politica y Sociedad, 5: 89-105.

- (1994): Productive assets, economic practices and relational interests. Some comments on Marxist class theory, ponencia presentada en el XIII Congreso Mundial de Sociología, Bielefeld.

- (1995): «El concepto de estructura de clases. Inventario de estrategias constructivas y esbozo de una propuesta, en J. Carabaña (ed.), Desigualdad y clases sociales, Madrid, Visor-Fundación Argentaria.

CARABAÑA, J. (1992): "Clase social e ingresos», Boletín Igualdad, 3: 5-7.

- (1994): «Educación y diversidad de clases sociales», en F. Fernández Palomares y A. Granados (eds.), Sociología de la educación. Viejas y nuevas cuestiones, Málaga, Clave.

- (1995): «Esquemas y estructuras», en J. Carabaña (ed.), Clases y desigualdad social, Madrid, Visor-Fundación Argentaria.

Carchedi, G. (1977): On the Economic Identification of Social Classes, Londres, Routledge \& Kegan Paul.

Carling, A. (1991): Social Division, Londres, Verso.

- (1994): «On Social Class Confusion», Rationality and Society, 6 (2): 190-217.

Clement, W., y Myles, J. (1994): Relations of Ruling: Class and Gender in Postindustrial Societies, Montreal, McGill-Queen's University Press.

CoHen, G. A. (1988): History, Labour and Freedom, Oxford, Clarendon.

Crompton, R. (1993): Class and Stratification: An Introduction to Current Debates, Cambridge, Polity Press.

De Francisco, A. (1992): "¿Qué hay de teórico en la "teoría” marxista de las clases?», Zona Abierta, 59-60: 157-186.

- (1996): Sociología y cambio social, Barcelona, Ariel.

Elster, J. (1985): Making Sense of Marx, Cambridge, Cambridge University Press.

Erikson, R., y Goldthorpe, J. H. (1993): The Constant Flux: A Study of Class Mobility in Industrial Societies, Oxford, Clarendon.

Goldthorpe, J. H. (1982): "On the service class, its formation and future», en A. Giddens y G. Mackenzie (eds.), Social Class and the Division of Labour, Cambridge, Cambridge University Press.

- (1987): Social Mobility and Class Structure in Modern Britain, Oxford, Clarendon, 2. ${ }^{\mathrm{a}}$ ed.

- (1995): "The service class revisited», en T. Butler y M. Savage (eds.), Social Change and the Middle Classes, Londres, University College London.

GoldThORPE, J. H., y MARSHALl, G. (1982): «The promising future of class analysis: a response to recent critiques», Sociology, 26 (3): 381-400.

GonZÁlez, J. J. (1992a): «El debate posmarxista sobre las clases», Política y Sociedad, 11: 27-48.

- (con J. Carabaña) (1992b): «La construcción empírica de las clases», Política y Sociedad, 11: 91-122.

- (1992c): Clases sociales. Estudio comparativo de España y la Comunidad de Madrid, Madrid, Consejería de Economía de la Comunidad. 
Johnson, T.; Dandeker, C., y Ashworth, C. (1984): The Structure of Social Theory, Londres, Macmillan.

KRECKEL, R. (1990): "New" Social Inequalities and the Renewal of the Theory of Social Inequalities», en S. R. Clegg (ed.), Organization Theory and Class Analysis, Nueva York-Berlín, De Gruyter.

Kumar, K. (1978): Prophecy and Progress. The Sociology of Industrial and Post-Industrial Society, Harmondsworth, Penguin.

Levey, G. B. (1996): "Theory Choice and the Comparison of Rival Theoretical Perspectives in Political Sociology", Philosophy of the Social Sciences, 26 (1): 26-60.

Mann, M. (1993): The Sources of Social Power. Vol. II: The rise of classes and nation-states, 17601914, Cambridge, Cambridge University Press.

Marshall, G., et al. (1988): Social Class in Modern Britain, Londres, Hutchinson.

MAYer, T. (1994): Analytical Marxism, Londres, Sage.

Mosterín, J. (1984): Conceptos y teorías en la ciencia, Madrid, Alianza.

Nisbet, R. (1959): "The decline and fall of social class», Pacific Sociological Review, 2: 11-17.

PAKUlSKi, J., y Waters, M. (1996): The Death of Class, Londres, Sage.

PARAmio, L. (1993): «El materialismo histórico como programa de investigación», en E. Lamo de Espinosa y J. E. Rodríguez Ibáñez (eds.), Problemas de teoría social contemporánea, Madrid, CIS.

PAWsON, R. (1989): A Measure for Measures, Londres, Routledge.

Porpora, D. (1987): The Concept of Social Structure, Westport, Greenwood Press.

- (1989): «Four Concepts of Social Structure», Journal for the Theory of Social Behaviour, 19 (2): 195-211.

POUlantZas, N. (1974): Las clases sociales en el capitalismo actual, Madrid, Siglo XXI, 1977.

Roemer, J. (1982): Teoría general de la explotación y de las clases, Madrid, Siglo XXI, 1989.

Runciman, W. G. (1968): “¿Clase, “status” y poder?», en J. A. Jackson (ed.), Estratificación social, Barcelona, Península, 1971.

Sorokin, P. A. (1956): Achaques y manias de la sociología moderna y ciencias afines, Madrid, Aguilar, 1957.

Urry, J. (1995): "Rethinking Class», en L. Maheu (ed.), Social Movements and Social Classes, Londres, Sage.

VAN PARIJS, P. (1981): Evolutionary Explanation in the Social Sciences, Londres, Tavistock.

- (1987): "A Revolution in Class Theory», reimpreso en E. O. Wright et al., The Debate on Classes, Londres, Verso, 1989.

- (1990): Le modèle économique et ses rivaux, París, Droz.

WaGNER, D. G. (1992): «Daring Modesty: On Metatheory, Observation, and Theory Growth», en S. Seidman y D. G. Wagner (eds.), Postmodernism and Social Theory, Oxford, Blackwell.

Wagner, D. G., y Berger, J. (1984): «Do Sociological Theories Grow?», American Journal of Sociology, 90 (4): 697-728.

Wilson, J. (1983): Social Theory, Englewood Cliffs, Prentice-Hall.

Wright, E. O. (1978): Clase, crisis y Estado, Madrid, Siglo XXI, 1983.

- (1979): Class Structure and Income Determination, Nueva York, Academic Press.

- (1980): "Class and Occupation", Theory and Society, 9 (1): 177-214.

- (1985): Classes, Londres, Verso.

- (1987): «Reflections on Classes», Berkeley Journal of Sociology, XXXII: 19-49.

- (1989): «Rethinking, once again, the concept of class structure», en E. O. Wright et al., The Debate on Classes, Londres, Verso.

- (1994): Interrogating Inequality, Londres, Verso.

- (1995): «Análisis de clase», en J. Carabaña (ed.), Desigualdad y clases sociales, Madrid, VisorFundación Argentaria.

Wright, E. O.; LeVIne, A., y Sober, E. (1992): Reconstructing Marxism: Essays on Explanation and the Theory of History, Londres, Verso.

Zelditch, M. (1992): «Problems and Progress in Sociological Theory», Sociological Perspectives, 35 (3): 415-431. 


\begin{abstract}
This paper aims to make a critical contribution to social class theory and analysis. The author begins by reflecting on the general nature of "class systems", their meaning and how they are formed, and goes on to propose a series of criteria for building a class system linked with the proposed analytic reconstruction of the historical materialism research programme.
\end{abstract}

